\title{
Artificial Intelligence in Government Services: A Systematic Literature Review
}

\author{
João Reis ${ }^{1(\sqrt{ })}$, Paula Espírito Santo ${ }^{2}$, and Nuno Melão ${ }^{3}$ \\ ${ }^{1}$ Institute of Social and Political Sciences (ISCSP) and GOVCOPP, \\ University of Lisbon, Lisbon, Portugal \\ jcgr@campus.ul.pt \\ ${ }^{2}$ Institute of Social and Political Sciences (ISCSP) and CAPP, \\ University of Lisbon, Lisbon, Portugal \\ paulaes@iscsp.ulisboa.pt \\ 3 Department of Management and CI\&DETS, \\ School of Technology and Management of Viseu, \\ Polytechnic Institute of Viseu, Viseu, Portugal \\ nmelao@estgv.ipv.pt
}

\begin{abstract}
The aim of this paper is to provide an overview on how artificial intelligence is shaping the digital era, in policy making and governmental terms. In doing so, it discloses new opportunities and discusses its implications to be considered by policy-makers. The research uses a systematic literature review, which includes more than one technique of data analysis in order to generate comprehensiveness and rich knowledge, we use: a bibliometric analysis and a content analysis. While artificial intelligence is identified as an extension of digital transformation, the results suggest the need to deepen scientific research in the fields of public administration, governmental law and business economics, areas where digital transformation still stands out from artificial intelligence. Although bringing together public and private sectors, to collaborate in the public service delivery, presents major advantages to policy makers, evidence has also shown the existence of negative effects of such collaboration.
\end{abstract}

Keywords: Digital transformation $\cdot$ Digital era $\cdot$ Artificial intelligence $\cdot$ Political science $\cdot$ Policy-makers $\cdot$ Government services $\cdot$ Systematic literature review $\cdot$ Technological development

\section{Introduction}

Buzzwords as digital disruption and digital transformation are predominantly used in business contexts. Although, in a much smaller scale, the digital era is also reaching new areas of study, such as the public administration [1]. In cases where governments have made huge investments in the introduction of online services to link government networks to citizens, the penetration of these services tended to be unsatisfactory and did not provide adequate returns on the investment e.g. [2]. Therefore, the low level of user acceptance of electronic government services is recognized as a huge, incumbent problem for policy makers, public administration managers and the community as a whole [3]. Moreover, according to Agarwal [4, p. 1] the "public administrators are 
unprepared for the challenges they must face in order to cope with this non-incremental and exponential changes, as many of the existing government structures and processes that have evolved over the last few centuries will likely become irrelevant in the near future". Waves of technology, such as big data, autonomous agents and artificial intelligence (AI) have long been discussed and are reshaping government services. In most western democracies, in public administration, the real danger is represented by researchers and practitioners who are divorced from the world of public administration and are engaged in discussion and making technological decisions without understanding the implications for governance of the administrative state [5]. In line with this background, there is an emerging need for holistic understanding of the range and impact of AI-based applications and associated challenges [6].

Thus, in this article we will investigate the phenomena from two different perspectives: In a first perspective, we will analyse the digital revolution from a macro perspective, by examining that countries who have invested on artificial intelligence and how these governments have succeeded in doing so. Secondly, we intend to provide insightful recommendations on which areas artificial intelligence may be implemented at a governmental level.

Both scholars and practitioners are peremptory on the relevance of education and governmental investment to AI advancements. For instance, Mikhaylov et al. [7, p. 1] argues that "AI grand challenge requires collaboration between universities and the public and private sectors", while Bughin et al. [8] states that public education systems and workforce training programs will have to be rethought to ensure that workers have the skills to complement rather than compete with machines. The aforementioned studies consider AI challenges fragmented, given the lack of a comprehensive overview of AI challenges for the public sector. In that extent, our conceptual approach intends to analyse and compiles relevant insights and tendencies from the scientific and systematic literature review.

Motivated by the above, we have structured this article in four sections after the Introduction, as follows: We begin by a review of the basic concepts; secondly, we describe the methodological approach; then, we investigate the AI phenomenon from a theoretical perspective; in the last place, we provide the implications and suggestions for subsequent research and decisions at administrative and private levels.

\section{Conceptual Background}

The term "digital" comprises a pleonasm between humans and technologies. The malleability (e.g., re-programmability), homogeneity (e.g. standardized software languages) and transferability (e.g., ease of transferring digital representation of any object) is at the heart of technologies meshing digital, and often physical materiality, interwoven with human action [9]. In an attempt to define the essential elements of digital transformation, Reis et al. [1] carried out a systematic literature review. They have found that the most referenced elements by the majority of scholars were as follows: the technological element that is based on the use of new digital technologies 
such as social media, mobile, analytics or embedded devices; the organizational element that requires a change of processes or the creation of new business models; and social component that influences all aspects of human life, such as the goal of improving the customer experience.

Several concepts have been advanced to label digital transformation, and despite often used indistinctively in the literature, there are some differences. For example, digitization is the conversion of atoms to bits, digitalization is the transformation of all those bits into value [10]. Gobble [10] argues that digitalization may deliver some savings, most commonly, through efficiency gains and reduced error rates, but it does not change how the company does business. True digitalization, by contrast, changes everything as some authors e.g. [11] refer to it as "digital transformation". Digitization and digital transformation have been occurring in organizations since the 1950s [12]. Digital transformation may be defined as the use of technology to radically improve performance or reach of the enterprises, and it generally encompasses three key areas: customer experience, operational processes and business models [13]. The transformation of customer experience focus on what makes customer happier. While companies are using technology to enhance in-person sales conversation and multiple channels to enhance the customer integrated shopping experience. The transformation of operational processes enables companies to refocus their people on more strategic tasks as the technology gives executives deeper insights, allowing decision to be made on real-time and real data. Finally, the transformation of business models requires digitally modified businesses to share content across organizational silos; moreover, companies introduce digital products that complement traditional products and increasingly transform their multinational into truly global operations.

Digital technologies are bringing new fields of study to academics and innovative solutions to companies; however, established companies do not always understand their current business models well enough to know if it would suit a new opportunity or hinder it [14]. Digital talents and millennials are primary siloed in functions and academic disciplines that were designed to meet the needs of a past era - consequently, traditional academics should be encouraged to delve deeper in order to reach out more technological disciplines and transdisciplinary research agendas [15]. According to Demirkan and Spohrer [15], the new digital millennium requires new types of professionals and work practices as well as new types of citizens and social practices therefore, the authors encourage the development of T-shaped digital professionals and citizens' future-ready innovators who uniquely combine specialization and flexibility and who also use smart machines as assistants.

As advanced by Kostin [16], three global trends within the field of digital technologies are commonly investigated: artificial intelligence, block chain and big data we will focus on the first one. The AI was firstly initiated by McCarthy et al. [17], with an attempt to investigate how to make machines use language, from abstraction, to solve problems now reserved for humans. In 1995, Russell et al. [18] argued that several definitions and variations exists, but the concept could be defined broadly as intelligent systems with the ability to think and learn. Nowadays, it is commonly accepted that AI embodies a heterogeneous set of tools, techniques, and algorithms [19]. Jarrahi [19] reinforces that various applications and techniques fall under the broad umbrella of AI, ranging from neural networks to speech/pattern recognition, to 
genetic algorithms and to deep learning. Examples of these elements extend AI to include concepts as natural language processing, machine learning and machine vision. In general terms, public administration is also taking into account the AI capacities. This vision is shared by practitioners and consulting agencies, Capgemini [20] argues about the economic and societal benefits of AI to the public sector, or as they state: "AI helps us to enter a new era of sophisticated and smart public services".

\section{Methodology}

As the scientific production has been growing steadily, the scientific databases have played a key role in the diffusion of the scientific research. These databases (e.g., ISI, Scopus) make available statistical data, by displaying attractive and graphical knowledge, to allow researchers to understand and interpret real-life phenomenon's or scientific developments from virtually all areas of study. Due to its relevance, Pritchard [21, p. 348] has early defined the term bibliometric as the "application of statistical and mathematical methods set out to define the processes of written communication and the nature and development of scientific disciplines by using recounting techniques and analysis of such communication". Raan [22] also argued that bibliometric methods have been used to measure scientific progress in many disciplines of science and is a common research instrument for systematic analysis. Thus, the bibliometric method allows access to relevant knowledge about the status of scientific research in specific areas, which helps researchers to identify novel schemes among researchers [23]. In light with the above, the bibliometric analysis will use relevant quantitative data (e.g. dates) retrieved from the Web of Science database, that will support and enhance the findings of the content analysis.

The second technique is content analysis, which is relatively new instrument of analysis, dating back to the $18^{\text {th }}$ century in Scandinavia [24] and in a scientific perspective from the second half of the $20^{\text {th }}$ century on. It is identified as a systematic and replicable technique that allows compressing many words and sentences of text into fewer content categories based on explicit rules of coding, in order to allow researchers to make inferences about the author (individuals, groups, organizations, or institutions), the audience, and their culture in time [25]. Berelson [26, p. 18] defined content analysis as "a research technique for the objective, systematic and quantitative description of the manifest content of communication". However, Berelson's [26] definition did not capture the qualitative and latent perspective of the analysis [27, 28], but was later on debated by Krippendorff [29], which defined content analysis as a research technique for making replicable and valid inferences from texts (or other meaningful matter) to the contexts of their use. At first, content analysis was a timeconsuming process, due to the absence of adequate data analysis technologies. For some decades, researchers have available sophisticated software programs designed for computer-assisted qualitative data analysis, as e.g., NVIVO and MaxQDA. In practical terms, content analysis comprises three stages: stating the research problem, retrieving the text or the contents, and employing sampling procedures, and inference procedures of analysis. This technique considers the presence with which certain words or particular phrases occur in the text as a means of identifying its characteristics, 
the sentences in the document are transformed into numbers, and the number of times in which a word occurs in the text is taken as an indicator of its significance [30]. Content analysis is different from textual analysis, as it includes words and sentences, but it also be based on a linguistic set of instruments but also includes other items as the personalities, seconds and frames [31]. However, content analysis has several advantages, but, perhaps the most important is that it can be virtually unobtrusive [32], since besides being useful for analysing in-depth interview data, it may be also used nonreactively, which means that it is adequate to similar sources of data collection (e.g., digital libraries) that allow researchers to conduct analytic studies [33].

For decades, the Science Citation Index, now the WoS (Web of Science) (owned by Clarivate Analitics) was the only large multidisciplinary citation data source worldwide. Meanwhile, Scopus, provided by Elsevier, is a second comprehensive citation database [34]. Thus, the common way to systematically review the literature is to trace publications by using the WoS, which is still one of the worldwide most-used scientific database of peer-reviewed literature. The decision to choose this database is due to reasons of transparency and easy reproduction, since the results from Scopus were not very different from the ones from ISI WoS. The online search within WoS was conducted on October $8^{\text {th }}, 2018$, by including the keywords and operators "Government" AND "Digitalization" OR "Government" AND "Artificial Intelligence" in the Title, Abstract and Keywords field of the search-engine as displayed at Table 1.

Table 1. Methodological approach

\begin{tabular}{l|l|l|l}
\hline \multicolumn{2}{l}{ ISI web of science } & Government \\
\cline { 3 - 4 } & & Digitalization & $\begin{array}{l}\text { Artificial } \\
\text { intelligence }\end{array}$ \\
\hline Search & Title-Abstract-Keywords & 126 & 199 \\
\hline Language & English & 113 & 192 \\
\hline Categories & $\begin{array}{l}\text { Management, Business, Public } \\
\text { Administration, Economics, Political Science, } \\
\text { Social Sciences Interdisciplinary, Social } \\
\text { Issues, Operations Research Management } \\
\text { Science, Multidisciplinary Science }\end{array}$ & 37 & 40 \\
\hline $\begin{array}{l}\text { Document } \\
\text { types }\end{array}$ & $\begin{array}{l}\text { Proceedings paper } \\
\text { Articles }\end{array}$ & 35 & 39 \\
\hline
\end{tabular}

The review process was based on successive filters: (1) only articles written in English were deemed relevant for an accurate interpretation; (2) the selected documents were restricted to indexed scientific articles to ensure credibility, but also on conference papers with the intent of focusing on the most updated research; finally, (3) to gain a greater research focus our findings focused on, but were not limited to, areas of management, social sciences and political science. The WoS database has returned 74 research papers, as the exclusion rate is approximately $3 / 4$ of the initial search; this selection allowed us to gain an overall understanding of the subject under investigation and to focus on the results. This article presents the following research limitations: 
the literature review is confined to its keywords and it is possible that articles indirectly related may be missing. Due to space limitations, it was not possible to list all the references (74 articles) and the content analysis (e.g., coding, categories, subcategories). The author's working material may be provided on request by contacting the first author.

\section{Findings and Discussion}

\subsection{The Digital Scope and the Shift to Artificial Intelligence}

The analysis of the digital scope and the shift to other technologies is still a vibrant topic. Recently, Kostin [16] had researched the foresight of the global digital trends. The author examines the recent developments (e.g. artificial intelligence) of the global digital trends and investigates relevant digital technologies, which are crucial to frame future strategies not only for governments and citizens, but also for international companies. In light with the above, we analyse the AI paradigm, to this end we crosschecked the ISI WoS data to understand the extent of AI divergent and convergent relationships with the concept of digitalization.

Bani and Paoli [35] refer that governments have been moving away from the digitalization of documents, processes and decision-making, within the administration, towards a new model that involves citizens in the co-production and information sharing. Grandhi et al. [36] corroborates this view by stating that the current business environments are more uncertain than ever before, while understanding customer/ citizen behaviour is an integral part of an organization strategic planning and execution process. Organizations which embrace digitalization are seeing the investments made in IT infrastructure, Internet of Things, machine learning and AI getting more established and aiding the decision-making process [36].

In recent years, we have also witnessed the amalgamation of government services and electronic systems, and the United Kingdom (UK) is no exception. Citizens and the state interactions have changed focus towards human centred electronic approaches, by introducing citizens with electronic services that have simplified bureaucratic mechanisms and response time [37]. In sum, the UK and the most part of EU countries are not just digitalizing government processes, there are also moving forward by involving their citizens in co-producing knowledge and information sharing, while machine learning and AI are turning the decision-making process easier. An empirical research of Russo et al. [38] refers that the Italian government, which is the second worldwide highest investor on governmental digitalization (Fig. 1), is considering the introduction of several online and office access points to its services to increase the penetration of provision systems not requiring a direct interaction in public administration - they argue that the digitalization of processes can save resources. The Italian investment in research and new digital technologies are due to the significant investment of e-Government services in Europe, while the diffusion of e-government services in Italy is slightly behind the European Union (EU) investment average [38]. Figure 1 illustrates the countries that are investing on the digitalization of their governments and the ones which are investing on AI. 


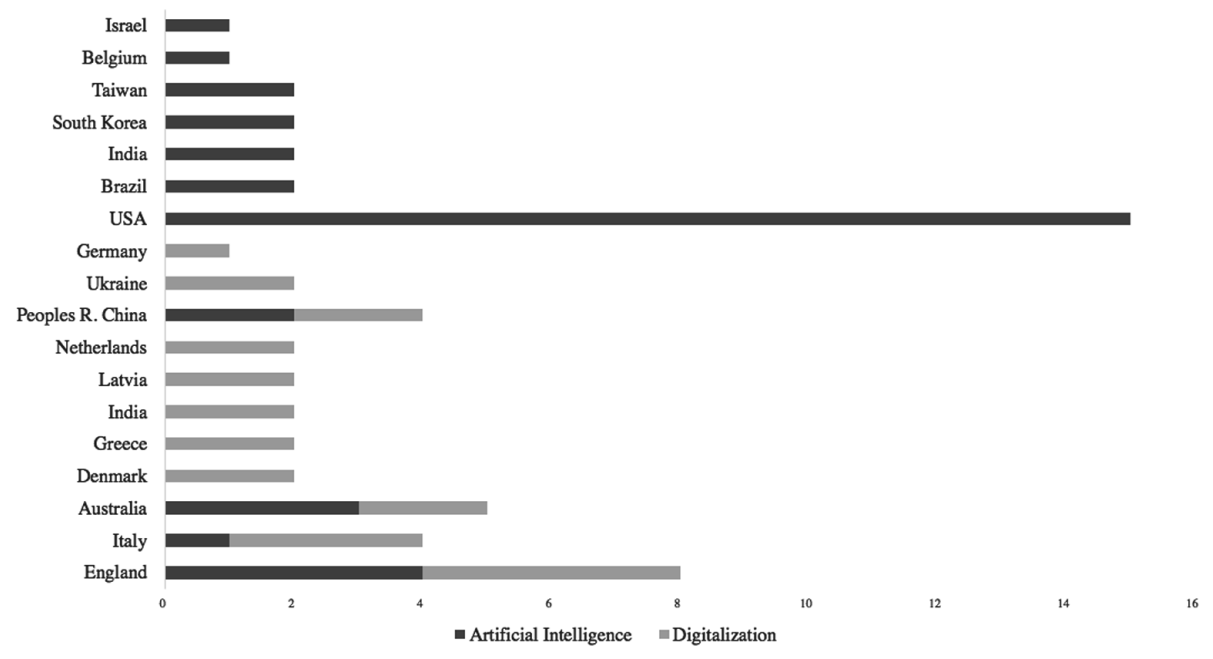

Fig. 1. Number of published articles by country concerning governmental digitalization and artificial intelligence (Source: based on ISI WoS data)

The British government had also made substantial practical contributions in the development of expert systems - the trend has been one of building from what others, particularly Americans, have done [39]. As governments cannot do the integration of AI into public service delivery on their own, the UK Government Industrial Strategy is clear that delivering on the AI grand challenge requires collaboration between universities and public private sectors [7]. Mikhaylov et al. [7] also argues that, despite the cross-sectorial collaborative approach is the norm in applied AI centres of excellence around the world, the popularity of this strategy entails serious management challenges that hinder their success. Therefore, the UK perspective to focus their AI investments on the synergies between the state and companies.

To the United States (US) maintain its innovative and technological competitive advantage, the US government, through its policy, is encouraging private companies to invest on new trends, such as Internet of Things, artificial intelligence, national security, and many other areas which are expected to evolve over the years ahead [40]. In sum, the US perspective is centred on governmental policies to enable and support AI technological developments. An example are the technological breakthroughs that have been sponsored by the US Government to gain military advantage - well-known technologies that challenge military traditional dominance includes autonomous vehicles, cyber technologies and artificial intelligence [41]. On the contrary, the UK and EU perspective is enhancement by collaborative synergies between companies and the state, thus this strategy somewhat enables the technological developments on AI to move forward. Although bringing together public and private sectors, collaboration in the public service delivery presents major advantages. Chou et al. [42] defines publicprivate partnership (PPP) as a strategy where governments encourage private institutions to support public construction projects by providing proper incentives based on collaboration with private institutions. It is worth noticing that Chou et al. [42] 
acknowledges existing negative effects of such collaboration, as disputes may occur during contract management. However, a research from Cheung et al. [43] highlights the PPP benefits on mitigating the shortage of governmental funding and avoid public investment restriction in the UK Most EU member states and also considers the PPPs as an important tool to attract additional financial resources [44] and, overall, the years to come we will find an increasing role for PPPs in the provision of public infrastructures and services [45]. We have also noticed a lack of research in recent years concerning the governmental process digitalization, when compared with the AI that has gained strength. Figure 2 presents a timeline of published articles regarding governmental digitalization and AI.

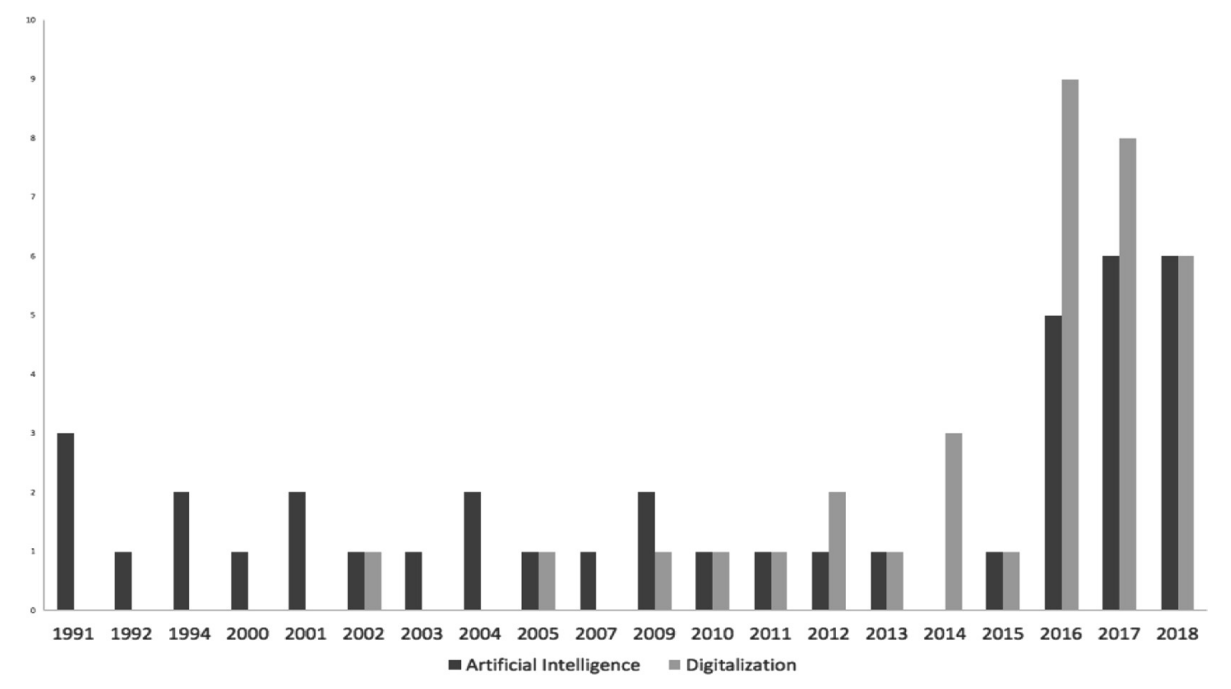

Fig. 2. Timeline of published articles regarding governmental digitalization and artificial intelligence (Source: based on ISI WoS data)

As far as digitalization is concerned, the year 2016 reached the top of scientific production, since digital technologies have had a strong impact on the governmental sector, and deserved wide scholar attention, vide e.g. digitalization of Finland's transport sector [46]. Moreover, citizens have also started to experience new technologies and applications, becoming co-producers of digital services [47]. On the other hand, recent scandals have undermined the digitalization progression vide [48], for instance the data protection showed how much sensitive we are in front of cyberattacks and vulnerable when it comes to our personal security [49,50]. The progress of published articles on AI is on a counter-cycle and its production is predictably increasing. Although slightly stable after 2017, the published articles on AI had increased exponentially from 2015 to 2016 which, according to Mikhaylov et al. [7], 
the observed growth is due the interest of public sector on data science and artificial intelligence capabilities to deliver policy and to generate efficiencies in highuncertainty environments.

\subsection{Will Artificial Intelligence Shape Digital Governments? if so, in Which Areas?}

According to Fig. 3, a greater emphasis has been given to the digitalization of the public administration and governmental law. Thus, it is clear that digital transformation is already changing the way how government services work, although with a smaller expression when compared with the business economics perspectives. The business economics stand out (Fig. 3), and represents the relationship between governments and companies, which supports our previous findings about the E.U governments efforts to establish partnerships with the private sector to underpin technological developments and it is at this stand that the digitalization and the artificial intelligence meet.

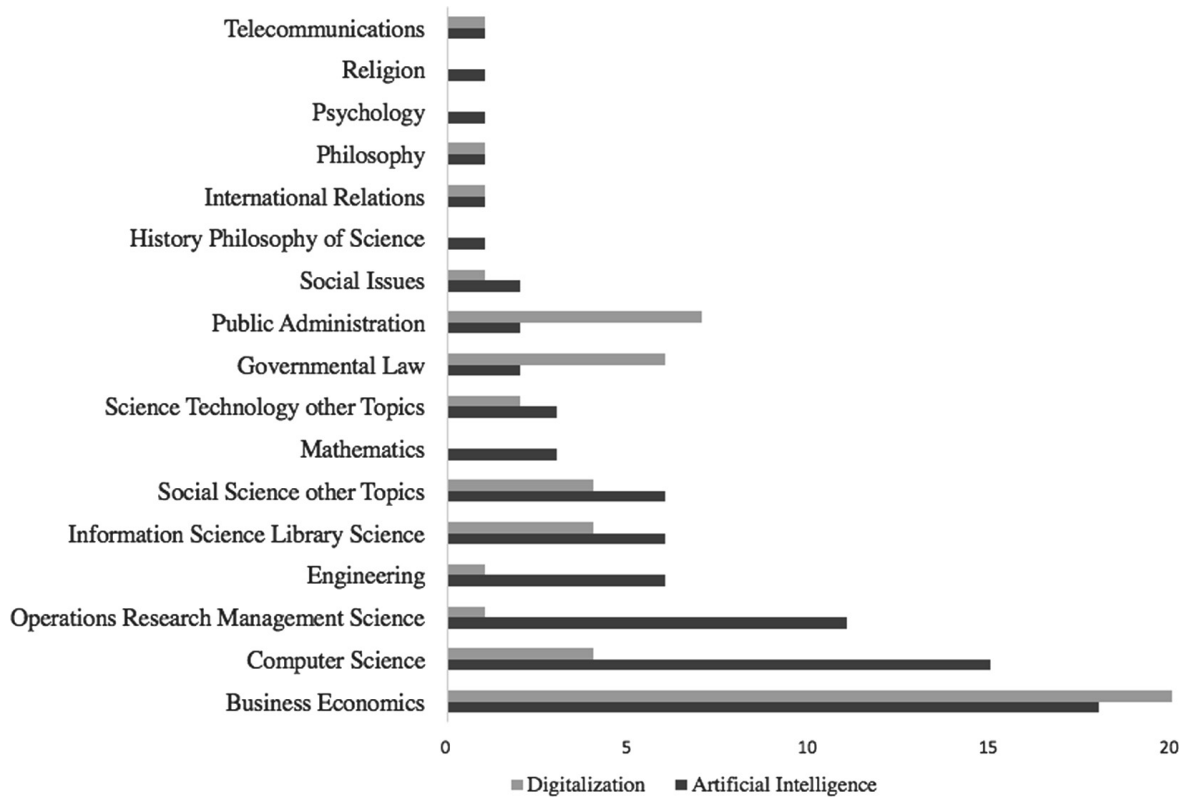

Fig. 3. Governmental research areas on digitalization and artificial intelligence (Source: based on ISI WoS data)

AI differs from digitalization at points essentially related to computer science and operations research, which are the foundation pillars for the development and implementation of the artificial intelligence at a governmental level. It is still hard to say that the AI is shaping digital governments, but it is clear at the point where partnering with private companies can improve the ways in which public administration and judicial services are delivered to its citizens. 


\section{Concluding Remarks}

As previously evidenced, governmental digitalization is currently involving citizens to co-produce information, which is enabling the decision-making process. It is known that currently digital transformation is mainly focused on business and industry areas, with less expression to governments, although it is a predictable game-changing tendency. On the other hand, what refers to AI, we concluded that Western countries, in particular the United States, are directly supporting its introduction in governmental policies. On the contrary, the EU governments are following a different strategy, as they underpin their technological developments in collaborative synergies with leading digital companies to move AI forward. Despite the association of these synergies brings several advantages, this strategy also entails serious management challenges that may hinder their success and therefore it deserves to be studied. It is still hard to say that $\mathrm{AI}$ is shaping digital governments. However, it is clear that $\mathrm{AI}$ is playing a strong influence on governments, that is leading to an increase of public and private investments.

While AI is identified as an extension of digital transformation, the results suggest to deepen the scientific research in public administration, governmental law and business economics. We do not believe the number of published articles on digital transformation should be lower than those on AI, because the latter refers to a digital technology within many other existing ones that are used in digital transformation. However, we identify the existing margin as an AI research opportunity within the digital transformation spectrum. Further research should not only focus on areas such as business economics, computer science or operations research, as it has been done so far, but also focus on the social issues and how the public administration can effectively improve the citizens lives through the use of AI.

\section{References}

1. Reis, J., Amorim, M., Melão, N., Matos, P.: Digital transformation: a literature review and guidelines for future research. In: Trends and Advances in Information Systems and Technologies, WorldCIST, pp. 411-421. Springer, Cham (2018)

2. Hung, S., Chang, C., Yu, T.: Determinants of user acceptance of the e-government services: the case of online tax filing and payment system. Gov. Inf. Q. 23(1), 97-122 (2006)

3. Lamberti, L., Benedetti, M., Chen, S.: Benefits sought by citizens and channel attitudes for multichannel payment services: evidence from Italy. Gov. Inf. Q. 31(4), 596-609 (2014)

4. Agarwal, P.: Public Administration Challenges in the World of AI and Bots. Public Administration Review (2018)

5. Barth, T., Arnold, E.: Artificial intelligence and administrative discretion: implications for public administration. Am. Rev. Public Adm. 29(4), 332-351 (1999)

6. Wirtz, B., Weyerer, J., Geyer, C.: Artificial intelligence and the public sector-applications and challenges. Int. J. Public Adm. 13(7), 1-20 (2018)

7. Mikhaylov, S., Esteve, M., Campion, A.: Artificial intelligence for the public sector: opportunities and challenges of cross-sector collaboration. Philos. Trans. R. Soc. A 376 (2128), 20170357 (2018) 
8. Bughin, J., Hazan, E., Ramaswamy, S., Chui, M., Allas, T., Dahlström, P., Henke, N., Trench, M.: Artificial intelligence-the next digital frontier. McKinsey Glob Institute. https:// www.mckinsey.de/files/170620_studie_aipdf. Accessed 11 Oct 2018

9. Hinings, B., Gegenhuber, T., Greenwood, R.: Digital innovation and transformation: an institutional perspective. Inf. Organ. 28(1), 52-61 (2018)

10. Gobble, M.: Digital strategy and digital transformation. Res.-Technol. Manag. 61(5), 66-71 (2018)

11. Matthias, L., Juliane, K., Peter, S.: The digital future has many names - how business process management drives the digital transformation. In: 6th International Conference on Industrial Technology and Management, pp. 22-26 (2017)

12. Heavin, C., Power, D.: Challenges for digital transformation-towards a conceptual decision support guide for managers. J. Decis. Syst. 27, 38-45 (2018)

13. Westerman, G., Bonnet, D., McAfee, A.: The nine elements of digital transformation', MIT Sloan Management Review (2014). http://sloanreview.mit.edu/article/the-nine-elements-ofdigital-transformation/. Accessed 11 Oct 2018

14. Sanchez, M., Zuntini, J.: Organizational readiness for the digital transformation: a case study research. Revista Gestão \& Tecnologia 18(2), 70-99 (2018)

15. Demirkan, H., Spohrer, J.: Commentary-cultivating T-shaped professionals in the era of digital transformation. Serv. Sci. 10(1), 98-109 (2018)

16. Kostin, K.: Foresight of the global digital trends. Strateg. Manag. 23(1), 11-19 (2018)

17. McCarthy, J., Minsky, M.L., Rochester, N., Shannon, C.: A proposal for the dartmouth summer research project on artificial intelligence, august 31, 1955. AI Mag. 27(4), 12 (2006)

18. Russell, S., Norvig, P.: Artificial Intelligence: A Modern Approach. Prentice-Hall, Englewood Cliffs (1995)

19. Jarrahi, M.: Artificial intelligence and the future of work: human-AI symbiosis in organizational decision making. Bus. Horiz. 61(4), 577-586 (2018)

20. Tinholt, D., Carrara, W., Linden, N.: Unleashing the potential of artificial intelligence in the public sector. Capgemini Consulting (2017)

21. Pritchard, A.: Statistical bibliography or bibliometrics? J. Doc. 25(4), 348-349 (1969)

22. Raan, A.: For your citations only? Hot topics in bibliometric analysis. Meas.: Interdisc. Res. Perspect. 3(1), 50-62 (2005)

23. Zyoud, S., Fuchs-Hanusch, D., Zyoud, S., Al-Rawajfeh, A., Shaheen, H.: A bibliometricbased evaluation on environmental research in the Arab world. Int. J. Environ. Sci. Technol. 14(4), 689-706 (2017)

24. Rosengren, K.: Advances in Scandinavia content analysis: an introduction. In: Rosengren, K.E. (ed.) Advances in Content Analysis. Beverly Hills, Sage (1981)

25. Mills, A., Durepos, G., Wiebe, E.: Encyclopedia of Case Study Research. SAGE Publications, California (2010)

26. Berelson, B.: Content Analysis in Communications Research. Free Press, New York (1952)

27. Hsieh, H., Shannon, S.: Three approaches to qualitative content analysis. Qual. Health Res. 15(9), 1277-1288 (2005)

28. Bengtsson, M.: How to plan and perform a qualitative study using content analysis. NursingPlus Open 2, 8-14 (2016)

29. Krippendorff, K.: Content Analysis. Sage Publications Inc., Beverly Hills (1980)

30. May, T.: Social Research: Issues, Methods and Process, 3rd edn. Open University Press, Buckingham (2001)

31. Santo, P.: Looking for social class and civil society in political discourse in Portuguese democracy (1976-2006) - content analysis approach. Comunicação Pública 10(8), 1-11 (2015) 
32. Webb, E., Campbell, D., Schwartz, R., Sechrest, L., Grove, J.: Nonreactive Measures in the Social Sciences. Houghton Mifflin, Boston (1981)

33. Berg, B.: Qualitative Research Methods for the Social Sciences, 4th edn. Allyn and Bacon, Boston (2004)

34. Raan, A.: Advances in bibliometric analysis: research performance assessment and science mapping. Bibliometrics. Use Abuse Rev. Res. Perform. 3, 17-28 (2014)

35. Bani, M., De Paoli, S.: Ideas for a new civic reputation system for the rising of digital civics: digital badges and their role in democratic process. In: ECEG2013-13th European Conference on eGovernment: ECEG (2013)

36. Grandhi, B., Patwa, N., Saleem, K.: Data driven marketing for growth and profitability. In: 10th Annual Conference of the EuroMed Academy of Business (2017)

37. Zissis, D., Lekkas, D.: The security paradox, disclosing source code to attain secure electronic elections. In: Proceedings of the 9th European Conference on e-Government (2009)

38. Russo, C., Ghezzi, C., Fiamengo, G., Benedetti, M.: Benefits sought by citizens in multichannel e-government payment services: Evidence from Italy. Procedia-Soc. Behav. Sci. 109, 1261-1276 (2014)

39. Bench-Capon, T., Rada, R.: Expert systems in the UK: from AI to KBS. Expert Syst. Appl. 3 (4), 397-402 (1991)

40. Rao, G., Williams, J., Walsh, M., Moore, J.: America's seed fund: how the SIBR/STTR programs help enable catalytic growth and technological advances. Technol. Innov. 18(4), 315-318 (2017)

41. FitzGerald, B., Parziale, J.: As technology goes democratic, nations lose military control. Bull. Atomic Sci. 73(2), 102-107 (2017)

42. Chou, J., Hsu, S., Lin, C., Chang, Y.: Classifying influential for project information to discover rule sets for project disputes and possible resolutions. Int. J. Project Manag. 34, 1706-1716 (2016)

43. Cheung, E., Chan, A., Kajewski, S.: Reasons for implementing public private partnership projects: perspectives from Hong Kong, Australian and British practitioners. J. Prop. Invest. Financ. 27(1), 81-95 (2009)

44. Medda, F., Carbonaro, G., Davis, S.: Public private partnerships in transportation: some insights from the European experience. IATSS Res. 36(2), 83-87 (2013)

45. Iossa, E., Saussier, S.: Public private partnerships in Europe for building and managing public infrastructures: an economic perspective. Ann. Public Coop. Econ. 89(1), 25-48 (2018)

46. Leviäkangas, P.: Digitalisation of Finland's transport sector. Technol. Soc. 47, 1-15 (2016)

47. Björklund, F.: E-government and moral citizenship: the case of Estonia. Citizsh. Stud. 20(67), 914-931 (2016)

48. Arun, P.: Uncertainty and insecurity in privacyless India: a despotic push towards digitalisation. Surveill. Soc. 15(3-4), 456-464 (2016)

49. Power, D.: "Big Brother" can watch us. J. Decis. Syst. 25(sup1), 578-588 (2016)

50. Kushzhanov, N., Aliyev, U.: Digital space: changes in society and security awareness. Bull. Nat. Acad. Sci. Repub. Kaz. 1, 94-101 (2018) 